\title{
PENGARUH GAYA KEPEMIMPINAN DAN BUDAYA ORGANISASI TERHADAP KINERJA PEGAWAI PUSKESMAS MUARA KIBUL KECAMATAN TABIR BARAT KABUPATEN MERANGIN
}

\author{
Khairun A. Roni, Martyah \\ Program Studi Manajemen Fakultas Ekonomi \\ Universitas Muara Bungo
}

\begin{abstract}
ABSTRAK
Tujuan dilakukan penelitian ini adalah untuk mengetahui pengaruh gaya kepemimpinan dan budaya organisasi secara parsial maupun simultan terhadap kinerja Pegawai Puskesmas Muara Kibul Kecamatan Tabir Barat Kabupaten Merangin.

Metode penelitian ini bersifat Deskriptif Kuantitatif dan menggunakan analisa kualitatif untuk mendiskripsikan data-data. Populasi adalah Pegawai Puskesmas Muara Kibul Kecamatan Tabir Barat Kabupaten Merangin yang berjumlah 51 orang, sampel dalam penelitian ini atas dasar pertimbangan bahwa Kepala Puskesmas tidak termasuk dalam sampel maka sampel yang digunakan berjumlah 50 orang.

Hasil penelitian ini, uji parsial variabel gaya kepemimpinan (X1) didapatkan nilai thitung nilai thitung $(2.293)>$ tabel $(2,012)$, dan variabel budaya organisasi (X2) didapatkan nilai thitung (11.975) > ttabel $(2,012)$, sehingga H0 ditolak dan Ha diterima. Diperoleh nilai Fhitung adalah 148.471 lebih besar dari Ftabel sebesar 3.200. Sehingga H0 ditolak dan Ha ditterima. Maka dapat disimpulkan bahwa variabel gaya kepemimpinan (X1) dan budaya organisasi (X2) secara parsial maupun simultan berpengaruh positif dan signifikan terhadap kinerja (Y) Pegawai Puskesmas Muara Kibul Kecamatan Tabir Barat Kabupaten Merangin. Hasil uji Koefisien Determinasi (R2) diperoleh nilai R Square sebesar 0.899 atau 89,9\%, hal ini menunjukan bahwa kontribusi variabel gaya kepemimpinan dan budaya organisasi terhadap kinerja pegawai sebesar $89,9 \%$, sedangkan sisanya sebesar 10,1\% dipengaruhi oleh dimensi lain diluar penelitian.
\end{abstract}

Kata Kunci : gaya kepemimpinan, budaya organisasi, kinerja

\section{PENDAHULUAN}

Keberhasilan suatu organisasi tidak terlepas dari peningkatan sumber daya manusia yang unggul dan berkualitas, harus selalu dikelola dan ditekankan oleh organisasi untuk mendapat kinerja yang diharapkan. Oleh karena itu, peningkatan sumber daya manusia sangat diperlukan agar pegawai memiliki sikap dan perilaku yang baik yang dapat memberikan kontribusi yang baik kepada Instansi. (Susilaningsih, 2008).
Gaya kepemimpinan yang baik adalah gaya kepemimpinan yang dapat memberikan motivasi kerja pada bawahannya, seorang pemimpin harus melakukan berbagai keahlian, pengalaman, kepribadian dan motivasi setiap individu yang di pimpinnya. Gaya kepemimpinan yang efektif di butuhkan dalam suatu organisasi atau kantor untuk dapat meningkatkan kinerja semua pegawai dalam mencapai tujuan yang telah di tetapkan kantor (Widyatmini dan Hakim, 2008). 
Selain gaya kepemimpinan, keberhasilan suatu organisasi atau kantor dalam mencapai tujuannya dapat di pengaruhi juga oleh Budaya organisasi. Di mana budaya organisasi merupakan pola, norma, keyakinan, dan nilai-nilai yang berlaku dalam suatu kantor, pola, norma, keyakinan dan nilai tersebut dapat mempengaruhi tindakan atau perilaku sumber daya manusia atau pegawai yang ada dalam suatu organisasi atau kantor sehingga berimplikasi terhadap kinerja pegawai yang ada dalam suatu organisasi atau kantor. budaya organisasi adalah pokok penyelesaian masalah-masalah eksternal dan internal yang pelaksanaanya di lakukan secara konsisten oleh suatu kelompok yang kemudian di wariskan kepada anggota anggota baru sebagai cara yang tepat untuk memahami, memikirkan dan merasakan terhadap masalah-masalah yang terkait.

Kinerja merupakan suatu fungsi kemampuan pekerja dalam menerima tujuan pekerjaan. Tingkat pencapaian tujuan dan interaksi antara tujuan dan kemampuan pekerja, dapat di katakan bahwa pegawai memegang peranan penting dalam menjalankan segala aktivitas kantor agar dapat tumbuh dan berkembang mempertahankan kelangsungan hidup kantor (Gorden dalam Nawawi, 2006).

Upaya-upaya dalam meningkatkan kinerja pegawai selain pengendalian internal gaya kepemimpinan juga perlu di perhatikan. Seorang pemimpin yang ideal harus memiliki gaya kepemimpinan yang baik sehingga dapat meningkatkan kinerja pegawai Seorang pemimpin sangat perlu memperhatikan gaya kepemimpinan dalam proses mempengaruhi, mengarahkan kegiatan anggota kelompoknya serta mengordinasikan tujuan anggota dan tujuan organisasi agar keduanya dapat tercapai.

Jumlah penduduk menurut desa dalam wilayah kerja Puskesmas Muara Kibul Kecamatan Tabir Barat Kabupaten Merangin dapat kita lihat:

\section{Jumlah Penduduk Wilayah Kerja Puskesmas Muara Kibul, 2019}

\begin{tabular}{|c|l|c|}
\hline No & \multicolumn{1}{|c|}{ Desa } & Penduduk \\
\hline 1 & Muaro Langeh & 212 \\
\hline 2 & Tanjung Putus & 595 \\
\hline 3 & Tanjung Beringin & 210 \\
\hline 4 & Pulau Tebakar & 209 \\
\hline 5 & UPT Pulau Tebakar & 239 \\
\hline 6 & Baru Kibul & 179 \\
\hline 7 & Muara Kibul & 563 \\
\hline 8 & Pulau Lebar & 327 \\
\hline 9 & UPT Batang Kibul & 553 \\
\hline 10 & Sungai Tabir & 396 \\
\hline 11 & Telentam & 538 \\
\hline 12 & Ngaol Ilir & 680 \\
\hline 13 & Ngaol & 510 \\
\hline 14 & Air Liki & 569 \\
\hline 15 & Air Liki Baru & 174 \\
\hline \multicolumn{2}{|c|}{ Jumlah } & $\mathbf{5 . 9 5 4}$ \\
\hline
\end{tabular}

Sumber : Puskesmas Muara Kibul, 2019 


\section{Jurnal Manajemen Sains volume 1, Nomor 1, Januari 2021}

Berdasarkan hasil observasi awal peneliti di Puskesmas Muara Kibul diketahui bahwa

Kepala Puskesmas jarang berada di tempat sehingga selaku pimpinan dari Puskesmas kurang memiliki kemampuan dalam mengendalikan bawahan, hal ini terlihat dari banyaknya bawahan yang tidak berada di tempat saat jam kerja dengan alasan sarapan di luar Puskesmas dan terdapat beberapa pegawai yang pulang duluan sebelum jamnya pulang, kondisi ini juga menggambarkan kurangnya kemampuan pimpinan dalam memotivasi pegawai dalam bekerja.

Selain dari gaya kepemimpinan Kepala Puskemas yang kurang mendukung kinerja pegawai, budaya organisasi yang kurang baik juga terjadi di Puskesmas Muara Kibul, dimana terlihat dari kurangnya inisiatif pegawai untuk melayani masyarakat ketika masyarakat datang, masyarakat harus bertanya kesana-kemari untuk mendapatkan pelayanan, tanpa adanya pegawai yang berusaha untuk menyapa terlebih dahulu.

Berdasarkan fenomena di atas penulis tertarik untuk melakukan kajian penelitian dengan judul "Pengaruh Gaya Kepemimpinan dan Budaya Organisasi Terhadap Kinerja Pegawai Puskesmas Muara Kibul Kecamatan Tabir Barat Kabupaten Merangin."

\section{Gaya Kepemimpinan}

Menurut Tjiptono (2016) gaya kepemimpinan adalah suatu cara yang digunakan pemimpin dalam berinteraksi dengan bawahannya. Sementara itu, pendapat lain menyebutkan bahwa gaya kepemimpinan adalah pola tingkah laku (kata-kata dan tindakan-tindakan) dari seorang pemimpin yang dirasakan oleh orang lain (Hersey, 2004).

Gaya kepemimpinan adalah perilaku atau cara yang dipilih dan dipergunakan pemimpin dalam mempengaruhi pikiran, perasaan, sikap dan perilaku para anggota organisasi bawahannya (Kartono, 2008).
Berdasarkan pengertian gaya kepemimpinan menurut pakar diatas, maka dapat disimpulakan gaya kepemimpinan adalah (leadership styles) merupakan cara yang diambil seseorang dalam rangka mempraktekkan kepemimpinanannya. Gaya kepemimpinan bukan suatu bakat, sehingga dapat dipelajari dan dipraktekkan dan dalam penerapannya harus disesuaikan dengan situasi yang dihadapi. Gaya kepemimpinan merupakan perilaku pimpinan terhadap pengikutnya, atau cara yang dipergunakan pemimpin dalam mempengaruhi para pengikutnya .

\section{Budaya Organisasi}

Menurut Robbins (2012) budaya organisasi merupakan sistem makna bersama yang dianut oleh anggota-anggota yang membedakan suatu organisasi dari organisasi lain. Sistem makna bersama ini, bila diamati dengan lebih seksama, merupakan seperangkat karakteristik utama yang dihargai oleh suatu organisasi. Budaya organisasi berkaitan dengan bagaimana karyawan mempersepsikan karakteristik dari suatu budaya organisasi, bukan dengan apakah para karyawan menyukai budaya atau tidak.

Ndraha (2006), mengartikan budaya organisasi adalah sebagai potret atau rekaman hasil proses budaya yang berlangsung dalam suatu organisasi atau perusahaan pada saat ini.

\section{Kinerja}

Robbins (2012) mengatakan bahwa kinerja merupakan fungsi interaksi dari kemampuan, motivasi dan kesempatan. Kinerja pada dasarnya adalah apa yang dilakukan atau tidak dilakukan oleh karyawan. Kinerja merupakan hal yang sangat penting dalam suatu perusahaan untuk mencapai tujuannya.

Kinerja dapat diartikan sebagai prestasi atau efektifitas oprasional suatu 
organisasi dan karyawan yang didasarkan pada sasaran standart dan kriteria yang telah ditetapkan sebelumnya. Kinerja adalah hasil kerja yang dapat dicapai oleh seseorang atau kelompok orang dalam suatu organisasi baik secara kuantitatif, sesuai dengan kewenangan dan tugas tanggung jawab masing-masing, dalam upaya mencapai tujuan organisasi yang bersangkutan secara legal, tidak melanggar hukum dan sesuai dengan moral atau etika.

\section{METODOLOGI PENELITIAN}

metode penelitian ini adalah metode pendekatan kuantitatif, karena penelitian ini disajikan dengan angka-angka. Hal ini sesuai dengan pendapat Arikunto yang mengemukakan penelitian kuantitatif adalah pendekatan penelitian yang banyak dituntut menggunakan angka, mulai dari pengumpulan data, penafsiran terhadap data tersebut, serta penampilan hasilnya (Arikunto 2006).

Adapun teknik pengambilan sampel yang digunakan dalam penelitian ini adalah
Purposive Sampling. Menurut Sugiyono (2010) Purposive Sampling adalah teknik untuk menentukan sampel penelitian dengan beberapa pertimbangan tertentu yang bertujuan agar data yang diperoleh nantinya bisa lebih representatif. Pemilihan sampel dalam penelitian ini atas dasar pertimbangan bahwa Kepala Puskesmas tidak termasuk dalam sampel maka sampel yang digunakan berjumlah 50 orang.

HASIL PENELITIAN DAN
PEMBAHASAN
Hasil Uji t (Parsial)
Uji $\mathrm{t}$ dalam penelitian ini
dilakukan dengan tingkat signifikansi $\alpha=$
$0,05$. Sementara nilai $\mathrm{t}_{\text {tabel }}$ pada $\alpha=0,05: 2$
$=0,025$ (uji dua sisi) dengan derajat
kebebasan atau degree of freedom (df) n-k
dimana $\mathrm{n}=$ banyak sampel dan $\mathrm{k}=$
banyaknya variabel bebas dan terikat, maka
$50-3=47$ diperoleh $t_{\text {tabel }}$ sebesar 2,012.

\section{Coefficients $^{\mathrm{a}}$}

\begin{tabular}{|c|c|c|c|c|c|c|c|c|}
\hline \multirow{2}{*}{\multicolumn{2}{|c|}{ Model }} & \multicolumn{2}{|c|}{$\begin{array}{c}\text { Unstandardized } \\
\text { Coefficients }\end{array}$} & \multirow{2}{*}{$\begin{array}{c}\begin{array}{c}\text { Standardized } \\
\text { Coefficients }\end{array} \\
\text { Beta }\end{array}$} & \multirow[b]{2}{*}{$\mathrm{t}$} & \multirow[b]{2}{*}{ Sig. } & \multicolumn{2}{|c|}{$\begin{array}{l}\text { Collinearity } \\
\text { Statistics }\end{array}$} \\
\hline & & B & $\begin{array}{l}\text { Std. } \\
\text { Error }\end{array}$ & & & & $\begin{array}{c}\text { Toleranc } \\
\mathrm{e}\end{array}$ & VIF \\
\hline \multirow[t]{3}{*}{1} & (Constant) & 1.094 & 3.037 & & .360 & .720 & & \\
\hline & $\begin{array}{l}\text { Gaya } \\
\text { Kepemimpinan }\end{array}$ & .226 & .098 & .158 & 2.293 & .026 & .452 & 2.210 \\
\hline & $\begin{array}{l}\text { Budaya } \\
\text { Organisasi }\end{array}$ & .653 & .055 & .825 & $\begin{array}{r}11.97 \\
5\end{array}$ & .000 & .452 & 2.210 \\
\hline
\end{tabular}

a. Dependent Variable: Kinerja

Pegawai

Sumber: Output SPSS (olah data) 
Berdasarkan tabel di atas dapat dijelaskan sebagai berikut:

a. Hasil uji t untuk variabel gaya kepemimpinan $\left(\mathrm{X}_{1}\right)$

Hasil uji parsial, variabel gaya kepemimpinan $\left(\mathrm{X}_{1}\right)$ berpengaruh signifikan terhadap kinerja (Y) Pegawai Puskesmas Muara Kibul Kecamatan Tabir Barat Kabupaten Merangin. Hal ini terlihat dari nilai $t_{\text {hitung }}(2.293)>t_{\text {tabel }}(2,012)$, sehingga $\mathrm{H}_{0}$ ditolak dan $\mathrm{H}_{\mathrm{a}}$ diterima. Artinya, secara parsial variabel gaya kepemimpinan berpengaruh terhadap kinerja Pegawai. $t_{\text {hitung }}$ positif artinya gaya kepemimpinan berpengaruh positif terhadap kinerja Pegawai Puskesmas Muara Kibul Kecamatan Tabir Barat Kabupaten Merangin. Jika gaya kepemimpinan semakin baik, maka akan semakin meningkat pula kinerja Pegawai Puskesmas Muara Kibul Kecamatan Tabir Barat Kabupaten Merangin.

b. Hasil uji t untuk variabel budaya organisasi $\left(\mathrm{X}_{2}\right)$

Hasil uji parsial, variabel budaya organisasi $\left(\mathrm{X}_{2}\right) \quad$ berpengaruh signifikan terhadap kinerja (Y) Pegawai Puskesmas Muara Kibul Kecamatan Tabir Barat Kabupaten Merangin. Hal ini terlihat dari nilai $t_{\text {hitung }}(11.975)>t_{\text {tabel }}(2,012)$, sehingga $\mathrm{H}_{0}$ ditolak dan $\mathrm{H}_{\mathrm{a}}$ diterima. Artinya, secara parsial variabel budaya organisasi berpengaruh terhadap kinerja Pegawai. $t_{\text {hitung positif artinya }}$ Kompensasi berpengaruh positif terhadap kinerja Pegawai Puskesmas Muara Kibul Kecamatan Tabir Barat Kabupaten Merangin. Jika disiplin kerja semakin baik, maka akan semakin meningkat pula kinerja Pegawai Puskesmas Muara Kibul Kecamatan Tabir Barat Kabupaten Merangin.

\section{Hasil Uji F (simultan)}

Uji $F$ dalam penelitian ini dilakukan dengan tingkat signifikansi $\alpha=0,05$. Sementara nilai $\mathrm{f}_{\text {tabel }}$ pada $\alpha$ $=0,05$ df $1(\mathrm{k}-1)$ atau $3-1=2$, dan df $2(\mathrm{n}-\mathrm{k})$ atau $50-3=47$ (n adalah jumlah kasus atau responden dan $\mathrm{k}$ adalah jumlah variabel bebas dan terikat), diperoleh $\mathrm{F}_{\text {tabel }}$ sebesar 3.200.

ANOVA $^{\text {b }}$

\begin{tabular}{|l|r|r|r|r|r|}
\hline Model & \multicolumn{1}{|c|}{$\begin{array}{l}\text { Sum of } \\
\text { Squares }\end{array}$} & df & Mean Square & F & Sig. \\
\hline 1 Regression & 3226.422 & 2 & 1613.211 & 209.186 & $.000^{a}$ \\
Residual & 362.458 & 47 & 7.712 & & \\
Total & 3588.880 & 49 & & & \\
\hline
\end{tabular}

a. Predictors: (Constant), Budaya Organisasi, Gaya

Kepemimpinan 


\begin{tabular}{|l|r|r|r|r|r|}
\hline & \multicolumn{1}{|c|}{ ANOVA $^{\text {S }}$} \\
Model & Squares & df & Mean Square & F & Sig. \\
\hline 1 Regression & 3226.422 & 2 & 1613.211 & 209.186 & $.000^{\mathrm{a}}$ \\
Residual & 362.458 & 47 & 7.712 & & \\
Total & 3588.880 & 49 & & & \\
\hline
\end{tabular}

b. Dependent Variable: Kinerja

Pegawai

Sumber: Output SPSS (olah data)

Berdasarkan output Anova di atas dapat dilihat bahwa nilai $F_{\text {hitung }}$ adalah 209.186 lebih besar dari $\mathrm{F}_{\text {tabel }}$ sebesar 3.200. Sehingga $\mathrm{H}_{0}$ ditolak dan $\mathrm{H}_{\mathrm{a}}$ ditterima. Maka dapat disimpulkan bahwa variabel gaya kepemimpinan $\left(\mathrm{X}_{1}\right)$ dan budaya organisasi $\left(\mathrm{X}_{2}\right)$ secara simultan berpengaruh positif dan signifikan terhadap kinerja (Y) Pegawai Puskesmas Muara Kibul Kecamatan Tabir Barat Kabupaten Merangin.

\section{Koefisien Determinasi $\left(\mathbf{R}^{2}\right)$}

Model Summary ${ }^{b}$

\begin{tabular}{|c|c|c|c|c|}
\hline Model & $\mathrm{R}$ & R Square & $\begin{array}{c}\text { Adjusted R } \\
\text { Square }\end{array}$ & $\begin{array}{c}\text { Std. Error } \\
\text { of the } \\
\text { Estimate }\end{array}$ \\
\hline 1 & $.948^{\mathrm{a}}$ & .899 & .895 & 2.777 \\
\hline
\end{tabular}

a. Predictors: (Constant), Budaya Organisasi, Gaya Kepemimpinan

b. Dependent Variable: Kinerja Pegawai

Sumber: Output SPSS (olah data)

Berdasarkan output Model Summary di atas dapat dilihat nilai Adjusted $R$ Square sebesar 0.899 atau $89,9 \%$. Besarnya nilai tersebut menunjukan proporsi pengaruh yang dapat dijelaskan oleh variabel gaya kepemimpinan dan budaya organisasi secara bersama-sama terhadap besarnya variasi (naik turun) variabel terikat. Dimana variabel terikat (Y) dapat dijelaskan oleh kedua variabel bebas sebesar $89,9 \%$, sedangkan sisanya sebesar $10,1 \%$ dipengaruhi oleh dimensi lain diluar penelitian. 


\section{Jurnal Manajemen Sains volume 1, Nomor 1, Januari 2021}

\section{PENUTUP}

\section{Kesimpulan}

Berdasarkan hasil penelitian dan pembahasan pada bab sebelumnya, maka dapat ditarik kesimpulan sebagai berikut:

1. secara parsial variabel gaya kepemimpinan dan budaya organisasi berpengaruh positif dan signifikan terhadap kinerja Pegawai pegawai puskesmas muara kibul kecamatan tabir barat kabupaten merangin.

2. variabel gaya kepemimpinan $\left(X_{1}\right)$ dan budaya organisasi $\left(\mathrm{X}_{2}\right)$ secara simultan berpengaruh positif dan signifikan terhadap kinerja (Y) Pegawai Puskesmas Muara Kibul Kecamatan Tabir Barat Kabupaten Merangin.

\section{Saran}

Berdasarkan kesimpulan diatas penulis memberikan saran sebagai berikut:

1.Kepada manajemen Puskesmas Muara Kibul Kecamatan Tabir Barat Kabupaten Merangin agar dapat meningkatkan motivasi pegawai, hal ini dikarenakan rendahnya skor pada indikator tersebut.

2.Kepada manajemen Puskesmas Muara Kibul Kecamatan Tabir Barat Kabupaten Merangin agar dapat memperhatikan kompensasi yang diberikan kepada pegawai agar kinerja pegawai dapat ditingkatkan melalui pemberian kompensasi yang layak, hal ini dikarenakan rendahnya skor indikator tersebut.

3.Para peneliti selanjutnya yang akan mengkaji lebih dalam tentang penelitian yang sama diharapkan agar penelitian ini dapat menjadi salah satu informasi yang dapat digunakan untuk penelitian selanjutnya.

\section{DAFTAR PUSTAKA}

Arikunto, S. 2006. Metode Penelitian Kualitatif. Jakarta: Bumi Aksara.
Dede Sumarni. 2011. Pengaruh Kepemimpinan dan Budaya Organisasi Terhadap Kinerja Karyawan di PDAM Tirta Moedal Kota Semarang. Skripsi Universitas Negeri Semarang 2011.

Dessler, Gary. 2003, Manajemen Sumber Daya Manusia. Jilid II. Edisi 10. Penerbit PT Indeks: Jakarta.

Hasibuan, Malayu S.P. 2007. Manajemen Sumber Daya Manusia Perusahaan, Bandung: PT. Bumi Aksa. 2009. Manajemen Sumber Daya Manusia Edisi Revisi. Jakarta: Bumi Aksara.

Hendriawan. 2014. Pengaruh Gaya Kepeimpinan dan Budaya Organisasi Terhadap Kinerja Karyawan pada PT. Dwimitra Multiguna Sejahtera di Kabupaten Konawe Utara Provinsi Sulawesi Tenggara. Skripsi Fakultas Ekonomika dan Bisnis Universitas Hasanuddin Makassar.

Kartono, Kartini. 2008: Pemimpin dan Kepemimpinan. Jakarta : PT. Raja Grafindo Persada.

Nawawi, Hadari. 2006. Evaluasi dan manajemen kinerja di lingkungan perusahaan dan industri. Yogyakarta: Gadjah Mada Univercity Press.

Pabundu, Tika. 2006, Budaya Organisasi dan Peningkatan Kinerja Perusahaan, Jakarta: Cetakan Pertama, PT Bumi Aksara.

Simamora, Henry. 2006. Manajemen Sumberdaya Manusia. Yogyakarta: Sekolah Tinggi Ilmu Ekonomi YKPN. 
Sugiyono. 2015. Metode Penelitian Pendidikan (Pendekatan Kuantitatif, Kualitatif dan $R \& D$ ). Penerbit CV. Alfabeta: Bandung.

Susilaningsih, Nur. 2008. Pengaruh Kepemimpinan, Disiplin, Motivasi, Pengawasan, dan Lingkungan Kerja Terhadap Kinerja Pegawai (Studi Pada Badan Perencanaan Pembangunan Daerah Kabupaten Wonogiri. EXCELENT, vol 1, no 2.

Sutrisno, Edi. 2009. Manajemen Sumber Daya Manusia Edisi pertama. Jakarta: Kencana Prenada Media Group.

Teguh Rhiman Handoko. 2012. Pengaruh Kepemimpinan, Budaya Organisasi, Disiplin Kerja Terhadap Kinerja Karyawan Pada Pondok Serrata Hotel. Jurnal Universitas Semarang Volume 1 Nomor 32012.

Tika, P. 2006. Budaya Organisasi Dan Peningkatan Kinerja Perusahaan. PT Bumi Aksara. Jakarta.

Thoha, Miftah, 2010. Kepemimpinan Dalam Manajemen, Jakarta : Rajawali Pers.
Wahyuni, Evi. 2015. Pengaruh Budaya Organisasi dan Gaya Kepemimpinan Terhadap Kinerja Pegawai Bagian Keuangan Organisasi Sektor Publik Dengan Motivasi Kerja Sebagai Variabel Intervening (Studi Kasus Pada Pegawai Pemerintah Kota Tasikmalaya). Jurnal Nominal Vol. IV No.1 Tahun 2015.

Widiningsih Abas. 2010. Pengaruh kepemimpinan dan budaya organisasi terhadap kinerja karvawan pada PT.Bank Mega Semarang. Skripsi Universitc $\quad$ goro 2010.

Widyatmini, dan Luqman Hakim. 2008. Hubungan Kepemimpinan, Kompensasi, dan Kompetensi Terhadap Kinerja Pegawai Dinas Kesehatan Kota Depok. Jurnal Ekonomi Bisnis No.2 Vol.13. Hal: 163-170.

Winardi. 2007. Manajemen Perilaku Organisasi, Edisi Revisi, Jakarta, Kencana Prenada Media Group.

Wirawan. 2009. Evaluasi Kinerja Sumber Daya Manusia Teori Aplikasi dan Penelitian. Jakarta. Penerbit: Salemba Empat. 